\title{
Severe pulmonary disease and hyperviscosity in macroglobulinaemia
}

\author{
S. W. BANHAM \\ M.B., Ch.B.
}

\author{
M. C. BATESON \\ M.B., M.R.C.P.
}

\section{Ninewells Hospital and Medical School, Dundee}

\section{Summary}

A case of Waldenstrom's macroglobulinaemia with various clinical manifestations of the condition is presented. Hyperviscosity and respiratory complications are discussed with a brief review of the literature.

\section{Case Report}

A 60-year-old woman presented in March 1974 with a 3-month history of increasing fatigue, weight loss, intermittent abdominal pain and, finally, passing blood per rectum. There was a 16year history of asthmatic bronchitis, latterly treated with a salbutamol inhaler. On examination she was plethoric with signs of mild congestive cardiac failure. Coarse inspiratory and expiratory rhonchi were audible in both lung fields. There was smooth hepatomegaly to $3 \mathrm{~cm}$ below the costal margin. The haemogram was normal and sigmoidoscopy was negative to $15 \mathrm{~cm}$. Chest X-ray showed emphysema and minimal scarring at the right base (Fig. 1). However, barium enema and meal both showed changes consistent with a resolving ischaemic enterocolitis.

Four further admissions with general malaise, vomiting and altered bowel habit followed. She also experienced exacerbation of her asthma requiring

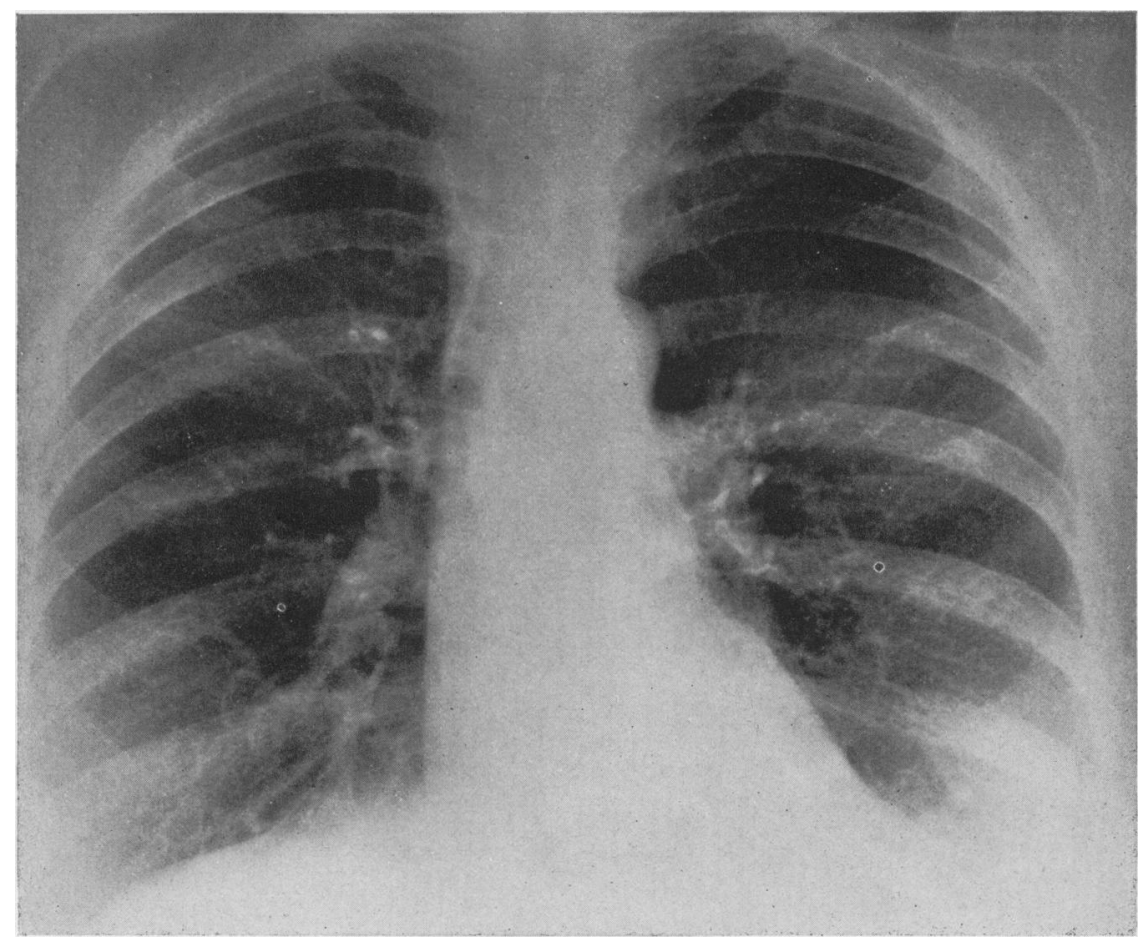

FIG. 1. Postero-anterior chest radiograph 29.4.74 
prednisolone $7.5 \mathrm{mg} /$ day. Persistently elevated erythrocyte sedimentation rates (Westergren, 80 $120 \mathrm{~mm} / \mathrm{hr}$ ) were recorded. Protein immunoelectrophoresis showed an abnormal monoclonal IgM band with IgM $30 \mathrm{~g} / 1$ (normal $0 \cdot 3-2.5 \mathrm{~g} / 1$ ), IgG $5.6 \mathrm{~g} / \mathrm{l}(7.0-18 \mathrm{~g} / \mathrm{l})$ and $\operatorname{IgA} 0.4 \mathrm{~g} / \mathrm{l}(0.5-4.5 \mathrm{~g} / \mathrm{l})$. The sternal marrow and a skeletal survey were normal. No clotting disturbance, cryoglobulins or hyperviscosity could be demonstrated at this time.

The patient was followed-up in an out-patient clinic, where she complained of a dry mouth. A Schirmer's test of less than $5 \mathrm{~mm}$ confirmed a diagnosis of Sjögren's syndrome. An episode of transient paraesthesiae of the right hand, of uncertain nature was also noted. She remained otherwise well until January 1976.

Then the patient was admitted to another hospital with a severe chest infection (Staphylococcus aureus) and right pleural effusion. Pleural aspiration was performed and antibiotic therapy instituted with gradual clinical improvement. Several further infections requiring in-patient treatment occurred over the next 2 months. The IgM level had risen to $44 \mathrm{~g} / \mathrm{l}$, the haemoglobin fell to $9.5 \mathrm{~g} / \mathrm{l}$ and $x$ light chains were detected in the urine.

Shortly afterwards she presented to the surgical wards with paraesthesiae and blue discoloration of the right thumb and forefinger. An epistaxis occurred on the ward. Following transfer to the medical unit another chest infection (Haemophilus influenzae) developed, again with a pleural effusion, and these were unaffected by a 7-day course of an appropriate antibiotic (Fig. 2). However, the addition of prednisolone $40 \mathrm{mg} /$ day produced marked clinical and $\mathrm{X}$-ray improvement over 5 days.

Resolution of the effusion revealed diffuse striation suggestive of parenchymal infiltration in the right lower lobe. Permanently impaired respiratory function has precluded lung biopsy.

Plasmapheresis $(1.51)$ was undertaken to lower plasma viscosity, and chlorambucil $5 \mathrm{mg}$ /day commenced. Four weeks later further plasmapheresis was necessary (Fig. 3), and her chlorambucil was increased to $10 \mathrm{mg} /$ day. Four months later she was well, with no marrow depression. There has been no further vascular impairment and dyspnoea is much improved concurrently with control of her macroglobulinaemia. The chest X-ray is comparable with that of 2 years previously.

\section{Discussion}

The term Waldenstrom's macroglobulinaemia has

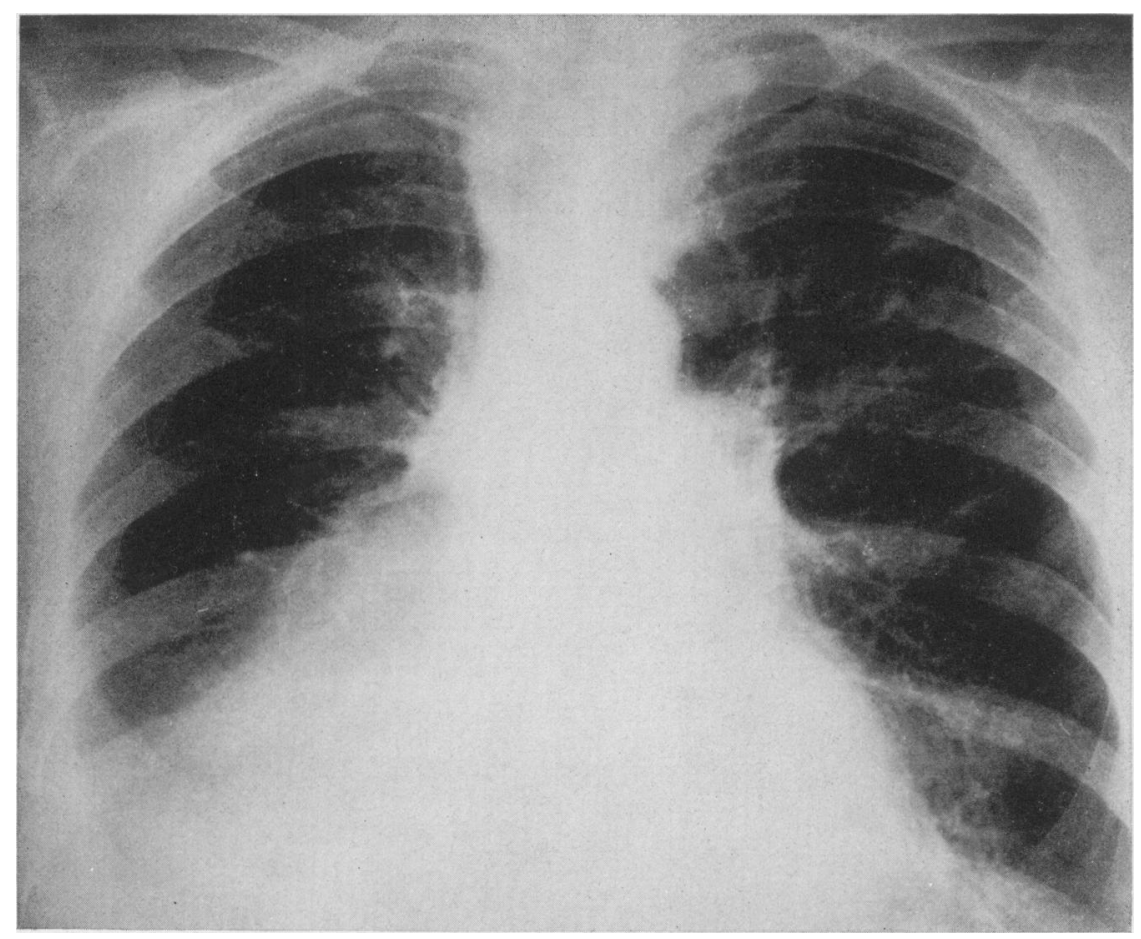




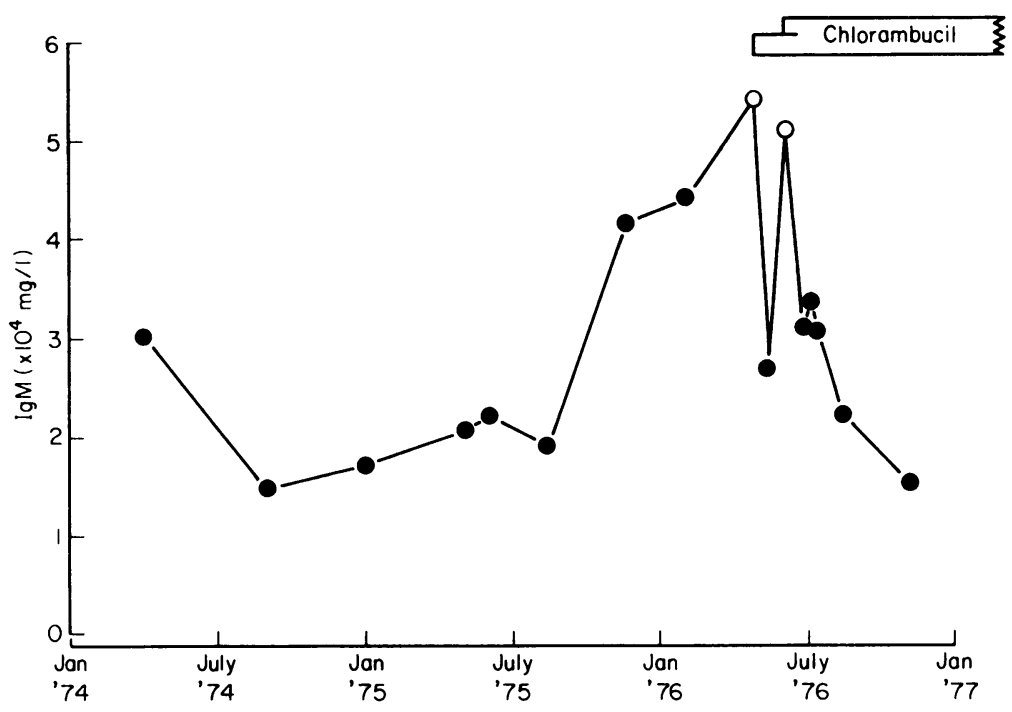

Fig. 3. Serial IgM levels and response to therapy. $\bigcirc$ indicates plasmapheresis at that point.

broadened to include a considerable spectrum of disease since the original description (Waldenstrom, 1944; Michaux and Heremans, 1969; Mackenzie and Fundenberg, 1972).

Hyperviscosity occurs in some $30 \%$ of individuals, and this patient illustrates several important aspects. There were typical symptoms (Fahey, Barth and Solomon, 1965) of bleeding, vague neurological disturbances and circulatory impairment (although the characteristic retinopathy was absent). There was good correlation between macroglobulin levels and symptoms of hyperviscosity (Mannik, 1974). The usual, if transient success of plasmapheresis in lowering viscosity was confirmed.

The pulmonary complications were of particular interest, considered against a background of asthmatic bronchitis treated with steroids. Bolinelli et al. (1970) differentiate three broad groups of pulmonary disease in macroglobulinaemia; infections; specific infiltrates-including effusions, parenchymal infiltrates, pseudotumours and bronchial infiltrates; and 'associated' lung disease, e.g. tuberculosis.

Another recent review of fifteen patients with respiratory complications (Winterbrauer et al., 1974) lends further support to this classification. Parenchymal infiltration and effusions predominated and the overall incidence of lung involvement was high in this series. These reports contrast with earlier work (McCallister et al., 1967) in which pulmonary manifestations receive little mention. It now seems established that pulmonary involvement should be sought whenever the diagnosis of Waldenstrom's macroglobulinaemia is made.

\section{Acknowledgments}

We are indebted to Professor I.A.D. Bouchier for permission to report this patient; and to Dr P. E. G. Mitchell and the Department of Biochemical Medicine for advice and skilled technical assistance.

\section{References}

Bolinelli, R., Carles, P., de Boissezon, J.-F., Bierme, R. \& Pusol, M. (1970) Formes respiratoires de la macroglobulinémie de Waldenstrom. Journal Français de Médecine et Chirurgie Thoraciques, 24, 437.

Fahey, J.L., Barth, W.F. \& Solomon, A. (1965) Serum hyperviscosity syndrome. Journal of the American Medical Association, 192, 464.

McCallister, B.D., Bayrd, E.D., Harrison, E.G. \& MCGuCKIN, W.F. (1967) Primary macroglobulinemia: Review with a report on 31 cases and notes on the value of continuous chlorambucil therapy. American Journal of Medicine, 43, 394.

MACKenZIE, M.R. \& Fundenberg, H.H. (1972) Macroglobulinemia: An analysis of forty patients. Blood, 39, 874.

ManNIK, M. (1974) Blood viscosity in Waldenstrom's macroglobulinemia. Blood, 44, 87.

MichauX, J. \& Heremans, J.F. (1969) Thirty cases of immunoglobulin disorders other than myeloma or macroglobulinemia. American Journal of Medicine, 46, 562.

WALDENSTROM, J. (1944) Incipient myelomatosis or 'essential' hyperglobulinaemia with fibrinogenopenia - a new syndrome. Acta medica scandinavica, 117, 216.

Winterbrauer, R.H., Riggins, R.C.K., Griesman, F.A. \& BAUERMEISTER, D.E. (1974) Pleuropulmonary manifestations of Waldenstrom's macroglobulinemia. Chest, 66, 4. 